\title{
MERCADO, TRADUÇÃO E REDE ELETRÔNICA: DISCURSIVIDADES EM PAUTA
}

\author{
GIOVANA CORDEIRO CAMPOS ${ }^{1}$
}

Instituto de Letras - Departamento de Letras Estrangeiras Modernas

Universidade Federal Fluminense

Campus do Gragoatá - Niterói/RJ

Rua Prof. Marcos Waldemar de Freias, s/n - Niterói - TRJ - Brasil

giovanacordeirocampos@gmail.com

\begin{abstract}
Resumo. Este trabalho tem como objetivo refletir sobre a relação entre tradução e mercado de trabalho com o foco nos discursos sobre a tradução em circulação em sites de empresas que ofertam serviços de tradução na rede eletrônica. As ditas "novas tecnologias", como a internet, e fenômenos como a globalização, dentre outros, levaram a um crescimento gigantesco do volume de traduções, fortalecendo a necessidade da rapidez extrema para a sua produção e disseminação. Tomando como base os Estudos da Tradução em relação com o campo da Análise do Discurso francesa de Michel Pêcheux, buscamos entender como tais condições de produção constituem a forma como a tradução é falada, entendida e realizada no espaço mercadológico atual.
\end{abstract}

Palavras-chave: tradução; internet; mercado de trabalho; discurso.

\begin{abstract}
This paper aims to reflect on the relationship between translation and the labor market by focusing on the discourses on translation circulating on translation companies' websites that offer translation services on the World Wide Web. The so-called "new technologies", such as the web, and phenomena as globalization, among others, led to a massive growth of translations, while strengthening the need for extreme speed for its production and dissemination. Based on Translation Studies in relation to Pêcheux's French Discourse Analysis, we seek to understand how such conditions of production constitute the way translation is spoken, understood and realized in the present labor market.
\end{abstract}

Keywords: translation; internet; labor market; discourse.

\footnotetext{
${ }^{1}$ Doutora em Letras (2010, área de concentração em Estudos da Linguagem, Tradução) pela PUC-Rio. Professora Adjunta de Tradução no Departamento de Línguas Estrangeiras Modernas (GLE) da Universidade Federal Fluminense (UFF). Coordenadora do Laboratório de Estudos da Tradução Labestrad/UFF; atua também no Programa de Pós-Graduação em Estudos da Linguagem da UFF.
} 


\section{A CIRCULAÇÃO DE SABERES E A REDE MUNDIAL DE COMPUTADORES}

A busca pelo conhecimento caracteriza a história dos povos, os quais, desde sempre, procuram obter as descobertas uns dos outros. O intercâmbio cada vez maior de ideias e práticas, seja de forma consentida, por meio da celebração de acordos diversos, seja de forma clandestina ou pela imposição de um poder hegemônico, impulsiona $o$ compartilhamento de invenções diversas, as quais passam a ser compartilhadas e a alcançar espaços muito além de suas fronteiras. Foi assim, por exemplo, com a invenção da máquina de impressão por tipos móveis, de Gutemberg, no século XV, a qual revolucionou o modo de circulação de saberes, tendo acelerado a produção de livros ao torná-la mecanizada. O processo de apropriação das descobertas alheias, sobretudo na atualidade, ocorre de forma a conectar os povos, inclusive os mais distantes, fomentando a disseminação de conhecimentos técnicos, científicos, religiosos etc., ao mesmo tempo em que acelera a continuação do desenvolvimento da ciência, das tecnologias e de novos comportamentos.

Dentre os "novos" conhecimentos, destacamos, na contemporaneidade, as chamadas "novas tecnologias", como a Internet, possível a partir da invenção do microcomputador, no final do século XX, o qual, por sua vez, gerou uma grande revolução, substituindo a informação escrita (analógica) pela informação digital. Com a internet, as informações passaram a circular, por assim dizer, de maneira instantânea. A internet surge também do desenvolvimento dos procedimentos de processamento de dados, voltados para a produção de comunicações interativas. A primeira rede de computadores - ARPANET (ARPA: Advanced Research Project Agency) - foi construída para comunicações entre a Universidade da Califórnia, o SRI (Stanford Research Institute), a Universidade de Utah e a Universidade da Califórnia em dezembro de 1969. Inicialmente, a principal atividade da ARPANET era o correio eletrônico, o qual deu início ao que hoje se chama comunicação "online". Surge, então, a ideia de uma rede internacional - Interconnected Networks - de onde deriva a denominação "Internet". Em 1990, o Departamento de Defesa dos E.U.A. substituiu a ARPANET pela NSFNET, que acabou por se popularizar como Internet:

Para expansão da utilização da Internet foi decisiva a criação da www - World Wide Web - criada por dois engenheiros do CERN - Centre Européen por la Recherche Nucléaire - Robert Caillaiu e Tim BernersLee, do HTML - HyperText Markup Language - e dos Browsers. O primeiro browser utilizado foi o LYNX que apenas permitia a transferência de textos. O MOSAIC, concebido na Universidade de Illinois - USA - já permitia a transferência de textos e imagens. Do MOSAIC derivaram os populares Netscape e Internet Explorer. (ALMEIDA, 2005, p. 4)

A partir daí, a internet passa a ser um sistema mundial público - "uma rede de redes" com a qual qualquer computador poderia se conectar, e a qual permite a transferência de informação entre computadores. Hoje, estamos interconectados à rede mundial também a partir de outra invenção tecnológica - os celulares e smartphones - e tal conectividade têm gerado profundas transformações nas relações humanas em geral, e nas trocas comerciais e profissionais em particular, nosso foco neste artigo. 
Atualmente, vivemos a era da "conectividade", cujos discursos sustentam uma visão do "estar na rede" como condição fundamental de existência do ser humano. Nesse mundo conectado e, portanto, globalizado, a informação adquire status de bem mais valioso.

Segundo Lemos (2005), a popularização da Internet provoca transformações não somente nas práticas sociais, mas também na forma de produzir e consumir a informação:

A cibercultura solta as amarras e desenvolve-se de forma onipresente, fazendo com que não seja mais o usuário que se desloque até a rede, mas a rede que passa a envolver os usuários e os objetos numa conexão generalizada. (LEMOS, 2005, p. 2)

Percebemos um formato de circulação de sentidos que é diferente, inclusive no sentido de que lugares que antes reclamavam uma presença material do sujeito passam a ser visitados virtualmente, em "tempo real" (SOUZA, 2016). Podemos exemplificar com visita a museus, bem como com palestras realizadas em grandes universidades.

As trocas comerciais e profissionais também sofrem transformações a partir das novas tecnologias. No caso do comércio, as compras online não demandam a presença do consumidor em lojas, por exemplo, sendo cada vez maior o número de consumidores que preferem adquirir seus bens sem sair de casa. $\mathrm{O}$ mesmo pode ser dito sobre a contratação de serviços, até porque é fácil e rápido encontrar profissionais de várias áreas, uma vez que empresas e profissionais apresentam seus produtos e serviços na rede mundial de computadores por meio de seus websites.

Para Lemos (2005), tecnologias como a da telefonia celular estão transformando o telefone móvel em um "controle remoto do cotidiano", o qual, ao lado da conexão sem fio - Wi Fi - oferecem novas dinâmicas de acesso e de uso da rede nas metrópoles contemporâneas (LEMOS, 2005, p. 1): tudo estaria disponível ao toque de um botão.

A rede, portanto, tem sido usada para vários propósitos, como o de instrumento de mobilidade e rapidez na troca de informações, como forma de manter e ampliar o círculo de amigos em "contato perpétuo" (KATZ \& AAKHUS apud LEMOS, 2005, p. 8), mas, também, como instrumento imprescindível ao universo do trabalho. No caso deste artigo, interessa-nos a relação entre a rede e a tradução no espaço das trocas mercadológicas efetuadas no espaço digital.

\section{TRADUÇÃO, TECNOLOGIA E MERCADO}

Um ponto relevante a ser mencionado é a relação entre a tradução e a globalização, a qual se intensifica a partir das tecnologias mais atuais. Segundo Giddens (1990), a globalização pode ser entendida como uma intensificação das relações sociais mundiais, as quais conectam diferentes e distantes localidades de um modo que os acontecimentos locais são de alguma forma modelados por eventos ocorridos a quilômetros de distância e vice-versa (GIDDENS apud CRONIN, 2017, p. 491, tradução nossa).

Para Cronin (2017), há muito a globalização tem sido uma característica da história da humanidade, haja vista os intercâmbios durante a Antiguidade, por exemplo. Contemporaneamente, porém, haveria diferenças marcantes. A primeira seria perceptiva, 
uma vez que o mundo hoje é compreendido como uma entidade global, e não como uma série de unidades locais. A segunda seria institucional, devido a um crescimento exponencial de organizações, como a ONU - Organização das Nações Unidas, o FMI Fundo Monetário Internacional, a OMC - Organização Mundial do Comércio e a OMS Organização Mundial da Saúde, dentre outras, e da criação da Comunidade Europeia. A partir dessas iniciativas coletivas, ações locais para evitar ou promover ações relativas a pandemias, catástrofes, pobreza etc. são vistas como insuficientes, havendo uma demanda por esforços coletivos em um nível transnacional (CRONIN, 2017, p. 491). Há, ainda, o aspecto econômico, o qual se liga à emergência de uma economia reticular, ou seja, a uma economia sustentada pela informática e pelas redes de telecomunicações, as quais permitem às empresas operarem em nível global e em tempo real. Desse modo, a produção e a distribuição de atividades podem ser coordenadas de qualquer lugar do globo, por meio da conectividade que é oferecida pela tecnologia da informação, facilitando a emergência e a perpetuação de megacorporações transnacionais. Temos, de acordo com Cronin, uma mudança de um modelo fordista para um pós-fordista. Se no primeiro o foco estava na produtividade em massa de bens padronizados, no segundo a ênfase recai na rapidez ("o mais rapidamente possível") em que se obtém o bem do produtor e se entrega ao consumidor (CRONIN, 2017, p. 492). No segundo modelo - pósfordista - a propaganda e o estabelecimento de uma marca são essenciais, uma vez que as preferências do consumidor mudam rapidamente. Uma consequência da conjunção entre o modelo pós-fordista e a economia reticular é a descentralização da produção (CRONIN, 2017, p. 492).

Se as grandes companhias não ficaram imunes ao desenvolvimento das tecnologias, tampouco o ficaram as pequenas e médias empresas, bem como os profissionais em geral. Segundo Hartley (2009), a rápida expansão da internet representou um grande impacto até para empresas menores, permitindo também a elas comercializarem seus produtos mundialmente. Nesse processo, os consumidores passaram a buscar por informações em suas respectivas línguas sobre os produtos, gerando uma grande demanda de traduções (HARTLEY, 2009, p. 106). Não somente as empresas perceberam a necessidade de tradução para aumento de vendas e lucro, como o próprio desenvolvimento do processo de globalização como um todo gerou uma demanda de traduções. Um bom exemplo é a criação do Google tradutor, possibilitando, ainda que com falhas, o acesso à tradução de várias páginas, bem como de textos dos usuários.

O aumento de demanda por traduções faz com que haja, consequentemente, uma ampliação do mercado de tradução. Nesse sentido, como aponta Hartley (2009), há um crescimento da parcela do mercado gerida por empresas de tradução ou prestadores de serviços linguísticos (p. 106). Segundo o autor, porém, é cada vez menor o número de tradutores que atuam diretamente com os clientes o que, a nosso ver, tem relação direta com a tendência da terceirização dos serviços na atualidade. Assim, cada vez mais o processo de tradução, como várias outras áreas, passa a seguir os modelos de gestão empresarial atuais.

É importante salientarmos o imenso o volume de traduções circulando na atualidade. Como apontou Hartley, em 2009, não é incomum a uma empresa multinacional processar mais de 1,5 bilhão de palavras relativas a 500 produtos e em mais de 30 línguas, sendo relevante apontar que as diferentes versões em cada língua precisam ser divulgadas simultaneamente em seus respectivos mercados (p. 106). Outros exemplos interessantes 
são reunidos por Cronin (2003), como o do Serviço de Tradução da Comunidade Europeia, o qual traduzia, à época de publicação do artigo, mais de um milhão de páginas por ano, empregando mais de 1500 tradutores em tempo integral (p. 111).

A economia reticular aliada à velocidade do processo de circulação de informações tem, portanto, efeito preciso sobre o mercado da tradução. Minimamente, podemos afirmar que os tradutores podem atuar (e frequentemente o fazem) dispersos pelo mundo, de forma remota, podendo um trabalho de tradução ser realizado a várias mãos, demonstrando uma fragmentação do ofício de tradutor (MELLO, 2016, p. 1650).

Como observa Hartley (2009), essas tendências são possibilitadas pela tecnologia, a qual acaba por modelar a forma como comunicamos e compartilhamos informações globalmente. Ao mesmo tempo, há "uma evolução contínua de outras tecnologias projetadas para sustentar o processamento de linguagem em geral e da tradução em particular" (p. 106), como a tradução por máquina e as CAT tools, ferramentas de tradução assistida, criadas para aumentar a produtividade dos tradutores. Tais ferramentas também apresentam forte impacto na forma como a tradução é entendida e comercializada na contemporaneidade.

A partir da necessidade de se alcançar padronização bem como maior velocidade na tradução comercial, foram desenvolvidos programas de tradução automática e sistemas de memórias de tradução, os últimos tendo se tornado ferramentas fundamentais para a realização da tradução como ocupação profissional, uma vez que as agências prestadoras de serviços de tradução os utilizam.

De forma geral, a tradução por máquina é entendida como a tradução de uma língua natural para outra por meio de programas de computador. Sua criação e utilização remontam à Guerra Fria, já com o objetivo de se economizar tempo, e com ele, dinheiro (WEININGER, 2004, p. 244). Inicialmente, seu uso era restrito, destinado a instituições de pesquisa e algumas empresas. Mas, com o advento da Internet, a tradução automática passou a ser usada também por leigos:

A quantidade de informações que podem ser repassadas através de redes é inimaginável, assim como o número de usuários de línguas completamente diferentes que têm acesso a essas informações. Somase a isso a aparente comodidade proporcionada por tais sistemas a usuários que precisam verter seus textos para outras línguas, porém, não possuem o conhecimento e a habilidade para tanto e se sentem atraídos pela velocidade com que isso poderia ser feito. (ALFARO, 1998, p. 370)

Os sistemas de memória de tradução, por sua vez, têm uma orientação oposta à da tradução automática, podendo ser entendidos como grandes bancos de dados, criados e alimentados pelos tradutores. Um sistema de memória de tradução baseia-se, como colocado por Weininger (2004), na "força bruta":

de ter um banco de dados de traduções anteriores semelhantes suficientemente grande que, a partir da repetição e reutilização de elementos parcialmente ou totalmente idênticos, faz surgir uma economia de tempo ao traduzir. Assim, ainda é o tradutor humano, 
agora "turbinado" pelo banco de dados, que traduz e decide sobre a usabilidade dos segmentos anteriormente traduzidos por ele ou outros tradutores humanos e é só ele quem adapta o material do banco de dados ao novo contexto.

Logo, para as duas ferramentas há o uso de computadores, porém, no caso da tradução por máquinas (ou tradução automática) o computador traduz todo o texto, sendo necessária a posterior participação de um tradutor humano (hoje chamado de pós-editor) para corrigir as falhas. Já no caso dos sistemas de memórias, o banco de dados é formado por escolhas de tradutores humanos, podendo ser reutilizadas. Logo, para a última, todo o processo de tradução depende das escolhas do tradutor humano. Segundo Stupiello (2014), a grande inovação dos sistemas de memória é a capacidade de recuperação e reaproveitamento de traduções anteriores. Além disso, o impacto do uso dessas ferramentas é enorme, tanto na definição de prazos, quanto na remuneração dos profissionais envolvidos (por exemplo, os termos e expressões que constam das memórias de tradução não são considerados para pagamento). Assim,

a crescente, e cada vez mais variada demanda do mercado de traduções, exige o desenvolvimento de habilidades e conhecimentos esperados de tradutores profissionais, particularmente, a capacidade de atuar em equipe e de empregar com eficiência as ferramentas tecnológicas disponíveis que possam aumentar a produtividade e a qualidade das traduções produzidas. Conforme defende Jiménez-Crespo (2015), "é consenso que a revolução da informação e da comunicação exerce influência massiva no campo profissional da tradução". (STUPIELLO, 2017, p. 82)

Em termos de um mercado globalizado, o uso dessas ferramentas permite que tradutores e agências possam se manter competitivos, sobretudo no que tange às exigências de rapidez. Segundo Perez (2001, apud STUPIELLO, 2014, p. 76), as transformações hoje vistas no mercado de traduções podem ser comparadas a uma "revolução industrial", a qual parece conduzir a uma automação do trabalho do tradutor com vistas à redução de custos e prazos. Nesse processo de automoção e de redução de custos, a divisão do trabalho implica diferentes tradutores atuando em diversos pontos diferentes do globo, dependentes da conexão eletrônica para recebimento das demandas tradutórias e posterior envio dos trabalhos traduzidos.

\section{A DINÂMICA DE OFERTA DE SERVIÇOS DE TRADUÇÃO NA INTERNET}

Para além de entendermos a rede como espaço de buscas terminológicas e conceituais, ou seja, como espaço para pesquisas que possam solucionar os problemas tradutórios específicos encontrados durante o processo de tradução, interessa-nos compreender a rede como local de oferta e procura de traduções, o que se relaciona ao mercado da tradução. O discurso da presença sine qua non na rede materializa-se não apenas no campo das relações sociais, culturais ou de entretenimento, para citar algumas, mas das relações profissionais. Nas diversas áreas, a Internet tem sido o principal meio de busca de informações, e no campo da oferta de produtos e serviços, ela mantém importante posição. São inúmeras as ofertas de serviços na rede, inclusive de tradução. No caso das 
empresas e escritórios de tradução presentes na Internet, há empresas estrangeiras, as quais ofertam sites traduzidos em português para atingirem também o potencial público consumidor brasileiro.

Uma vez que os discursos em circulação sobre a rede eletrônica, dentro e fora dela, a discursivizam como um espaço de integração indispensável, justificam-se investigações sobre a relação da tradução com a Internet, principalmente no que tange à representação da primeira - a tradução - no último - o espaço virtual. A rede compreende as mais diversas produções humanas, como fotos, vídeos, revistas acadêmicas, ofertas de serviços, mapas, relatos de viagem etc. e são múltiplas as possibilidades de pesquisa, ainda que seja feita uma restrição a materiais sobre tradução na rede. Logo, é necessário fazer recortes.

Desde 2010 temos pesquisado a relação entre tradução, academia e mercado, no intuito de pensar se os avanços dos chamados Estudos da Tradução conseguem se fazer circular no âmbito mercadológico. Nesse caminho, valemo-nos da rede eletrônica, com corpora formados manualmente a partir de produções publicadas no espaço digital. Nosso foco primeiramente recaiu sobre os editais para concursos de tradutores, disponíveis online. A partir desses editais, selecionamos apenas os destinados ao ingresso de tradutores e intérpretes em universidades públicas, o que nos levou à Classificação Brasileira de Ocupações - CBO, publicação do Ministério do Trabalho (também disponível no formato online) e que, apesar de não ter caráter regulamentador, legitima o que é exercer determinadas profissões no Brasil, inclusive a ocupação de tradutor e intérprete (CALDAS; MELLO, 2012 e 2014).

Para compor o corpus de análise que sustenta este artigo, nossa opção foi recolher na Internet sequências discursivas de textos de websites de empresas de tradução disponíveis online e que abordam a relação entre tradução e mercado. Alinhamo-nos aos Estudos da Tradução em sua relação com a Análise do Discurso de base pecheuxtiana, entendendo a tradução como um processo discursivo constituído no/pelo funcionamento de um sistema político-ideológico de base capitalista, o qual é estruturante, modelando e sustentando discursos outros, como o discurso empresarial e o discurso tecnológico, os quais se retroalimentam e também constituem os dizeres sobre tradução no âmbito mercadológico.

Para a composição do corpus de análise, usamos uma das ferramentas tecnológicas disponíveis na rede mundial de computadores: a ferramenta de busca do Google. Recolhemos 36 sites diferentes de empresas brasileiras e estrangeiras que ofertam serviços de tradução a consumidores brasileiros. Os parâmetros de busca envolveram a tradução especializada e empresas capazes de atender a demandas maiores de tradução, que se apresentam como empresas constituídas e que afirmam possuir um quadro de tradutores experientes. Essa opção se justifica na medida em que objetivamos pensar a forma pela qual circulam os dizeres sobre tradução em espaços de produção em massa de traduções.

Partimos do conceito de Lefevere (1992) de patronagem, considerando que o aceite de um trabalho de tradução implica uma forma de identificação do tradutor com a ideologia daquele que encomenda a tradução: patrocinador. Segundo Lefevere (1992, p. 15), uma tradução é realizada na medida em que é encomendada por um mecenas - o patrono. A patronagem se refere ao poder que as instituições, classes sociais, editores etc. exercem 
sobre os tradutores, os quais estão diretamente ligados "à ideologia dos patrocinadores que dominam a fase histórica do sistema social no qual o sistema literário está incluído" (tradução nossa).

Os sites recolhidos apresentam várias subdivisões, sendo que há sites em que pode ser encontrado um grande volume de textos. Em nossa pesquisa, optamos por investigar as subdivisões dedicadas a explicações sobre o processo de contratação de traduções e da produção das mesmas. Observamos que muitas delas oferecem seus serviços por modalidade de tradução, como serviços de tradução, de interpretação, de audiodescrição, não sendo as duas últimas o escopo de nossa pesquisa. Muitas empresas também anunciam as áreas de especialidade com as quais trabalham.

Ao analisarmos os respectivos sites, observamos uma forma-sujeito que pode ser considerada estruturante: a forma-sujeito capitalista. Segundo Pêcheux (1975), há um todo complexo com dominante no que se refere às formações discursivas - FDs (PÊCHEUX, 1988, p. 162). A FD dominante é a capitalista, que modela e sustenta os vários discursos outros que circulam na materialidade dos dizeres do site, constituindo o discurso mercadológico. A circulação de um discurso mercadológico de base capitalista era por nós esperado, uma vez que os websites funcionam como vitrines, nas quais a tradução é a mercadoria a ser comercializada. Pudemos observar que o discurso mercadológico se sustenta pelo funcionamento de dois discursos, que se retroalimentam: o discurso tecnológico e o discurso empresarial. No intuito de venderem seus produtos, praticamente todos os sites estudados apresentaram sequências discursivas ligadas à necessidade de qualidade, eficiência e rapidez. Enunciados como "garantimos a qualidade das traduções", "100\% de qualidade" e "alto nível de qualidade" podem ser encontrados em profusão, inclusive no formato de lista de itens ou como partes de textos relacionados com as vantagens de se escolher a empresa apresentada ${ }^{2}$. A questão a ser colocada é que a exigência de qualidade, em suas muitas formulações, chega ao fio do discurso pelo funcionamento do discurso empresarial. Em um sistema capitalista, em que o lucro é o centro de todas as atividades, a "otimização" do trabalho é fator fundamental.

Em seu estudo sobre o discurso da "Qualidade Total”, Amaral (2005) afirma:

Percorrendo a história da Qualidade Total, percebemos que, diferentemente do que se possa supor, a questão da "qualidade" sempre esteve presente no processo produtivo [...]. À "qualidade" associam-se produtividade e rentabilidade (lucro), constituindo um tripé que fundamenta o pensamento da gerência administrativa e acompanha a prática de gerenciamento do trabalho na sociedade contemporânea, seja qual for a designação que essa prática venha a receber [...] A "qualidade" se apresenta, hoje, revestida do "novo", mas comporta as

\footnotetext{
2 Os enunciados recortados se repetem no corpus, ora como itens de listas ora como parte de textos referentes a garantias e/ou vantagens oferecidas nos sites eleitos para análise. Por isso, optamos por discutilos em conjunto e não separadamente. Pela análise discursiva realizada, observamos o funcionamento da paráfrase. Segundo Orlandi (1998), "em termos discursivos, teríamos na paráfrase a reiteração do mesmo. Na polissemia, a produção da diferença" (p. 15). Assim, os processos parafrásticos envolvem a relação entre memória e historicidade, uma vez que há algo que se mantém no dizer, ou seja, se repete. Para Orlandi (2012), "a paráfrase é a matriz do sentido, pois não há sentido sem repetição, sem sustentação no saber discursivo" (p. 38).
} 
mesmas condições que a instituíram no processo de trabalho: a produtividade e o lucro.

Tais condições de produção são, portanto, as de uma sociedade capitalista, ainda que o discurso tecnológico e empresarial construa a "qualidade" em relação direta à satisfação do cliente moderno e bem informado. Isso não significa dizer que o capitalismo não se modifica, pois ele "cria e recria formas de relações de produção", mas cujo objetivo permanece como o da manutenção do lucro:

Entretanto, os métodos para a garantia do lucro de uma empresa têm se alterado para responder às modificações da sociedade capitalista neste final de século. Os fatores de produção, como a tecnologia, a força de trabalho e a divisão do trabalho, passam a ser organizados de forma mais acentuada em função de uma economia globalizada, distinguindose da produção do capitalismo do início do século, determinada pelos mercados nacionais". (AMARAL, 2005, p. 17)

A questão do "controle de qualidade" se constitui muito em função do fenômeno da produção em massa, em que se passou a ter uma linha de produção. Assim, se anteriormente a qualidade dependia do artesão, a partir do fenômeno da industrialização se fez necessário criar padrões para a inspeção dos produtos e, posteriormente, modelos para o controle dos produtos gerados nas linhas de produção em série. No Japão pós Segunda Guerra, o controle de qualidade criou contornos mais amplos, englobando as muitas fases de produção, visando, sobretudo, "à eliminação de defeitos" (AMARAL, 2005 , p. 164). Os sentidos em circulação para "controle de qualidade" se relacionavam à antecipação de resultados, para que fossem evitados "erros de fabricação". A partir da década de 1970, com a apropriação norte-americana do modelo japonês, os sentidos para "qualidade" passaram a considerar metas de produtividade, o que foi denominado de “administração por objetivos". Nas palavras de Amaral (2005),

a evolução dessa prática administrativa chegou aos anos 80 com a designação de Gestão pela Qualidade Total. Acompanhando a mudança de denominação, o referente também foi deslocado de 'produto sem defeito' para 'cliente satisfeito' [...] Hoje, na década de 90, a prática e o controle do trabalho é comumente designada com a expressão Qualidade Total. (p. 164)

Logo, não é aleatoriamente que o termo "qualidade" circula na maioria dos sites estudados; há um funcionamento ideológico-discursivo hegemônico que sustenta a relevância da "qualidade" dos produtos para venda, não apenas da tradução, mas de qualquer produto a ser comercializado, dentro e fora da rede. Há o funcionamento do jádito do interdiscurso, de saberes que chegam a partir de uma formação discursiva empresarial, sustentada pelos saberes da formação discursiva dominante: a capitalista. Observamos uma (re)produção de sentidos naturalizados, sem que seja de fato abordado o que significa uma "qualidade total" no contexto da tradução. No caso da qualidade em tradução, no fio do discurso circulam também sentidos de uma de "fidelidade total", tal como entendida pelo senso comum a partir de uma formação discursiva sobre a tradução: uma fidelidade absoluta, como se fosse possível tudo decodificar de um texto de partida para, então, tudo se redecodifica no texto de chegada. Cremos que a "qualidade total", no caso por nós estudado, também mobiliza tais "saberes" em circulação sobre a tradução, os quais se relacionam com saberes sobre a "língua" como objetivamente manipulável. 
A circulação de enunciados como " $100 \%$ de qualidade" adquire contornos mais interessantes quando observamos que algumas empresas oferecem distintas opções de tradução. No site $\mathrm{G}$, por exemplo, a primeira opção refere-se a uma espécie de tradução básica, a qual envolve diretamente a tradução por máquina, uma vez que, no lugar de "texto", comparece o termo "arquivo" na sequência discursiva de referência "o arquivo será traduzido". Não se trata de tradução de textos, mas de arquivos compartilhados online, os quais serão traduzidos por programas de auxílio à tradução. Temos, portanto, o funcionamento do discurso tecnológico, o qual atravessa o discurso sobre tradução, produzindo efeitos de sentido. Cabe dizer que não é mencionada a revisão. A segunda opção de tradução oferecida pela mesma empresa envolve a tradução 1 acrescida de uma revisão realizada pelo gestor, o qual corrige possíveis erros, sendo garantido " $100 \%$ de qualidade". O uso do termo "gestor" materializa o funcionamento do discurso empresarial no discurso sobre a tradução. É interessante observarmos que um terceiro nível de tradução é oferecido ao consumidor, o qual envolve acrescentar mais um passo na tradução: a revisão feita por um tradutor nativo. Vale dizer que somente a tradução do terceiro tipo é recomendada para publicação, sendo oferecido novamente " $100 \%$ de garantia".

Podemos considerar que os três tipos de tradução envolvem o uso de ferramentas de memórias, com a sobreposição do discurso tecnológico no discurso sobre tradução pela materialização do termo "arquivo" no passo 1 de todas as três opções. Todavia, o que mais nos chama a atenção na construção da superfície linguística analisada é que a "qualidade total" é oferecida tanto para o segundo quanto para o terceiro tipo de tradução, o que nos leva a tomar o enunciado "qualidade total" como uma evidência de sentido, construída pelo discurso empresarial, mas que, sob um exame mais profundo, caracterizase pela contradição. Parece haver um esvaziamento de sentidos no que tange à discursivização do termo "qualidade" no âmbito da oferta de traduções na Internet.

Segundo Pêcheux (1975), a contradição é própria do sujeito e do discurso. Na comparação entre os tipos de tradução, observamos que no fio do discurso circulam efeitos de sentido da qualidade perfeita por meio do funcionamento do discurso mercadológico-empresarial, ao mesmo tempo em que essa evidência de sentido é questionada pelo funcionamento de um discurso sobre a tradução que reconhece ser necessário algum grau de intervenção humana - a revisão - para a produção de traduções publicáveis, as únicas consideradas como tendo alta qualidade. A contradição opera nas fronteiras dessas formações discursivas, uma vez que a evidência de sentido da qualidade total é desconstruída pela materialização das possíveis falhas do processo.

A "garantia total" relacionada à tradução também se sustenta na ilusão da transparência de sentido, uma vez que desconsidera que a própria noção de "erro" pode variar sob condições de produção distintas. Assim, podemos dizer que, nas sequências analisadas, o discurso acadêmico da tradução até conseguiu circular em parte, mas não no que tange ao entendimento da tradução como processo discursivo e da interpretação como construção modelada pelas condições de sua produção.

De tudo o que foi exposto, cremos serem necessárias pesquisas mais abrangentes a respeito das relações entre tradução e mercado na rede eletrônica, não somente para uma compreensão mais aprofundada sobre a forma como o mercado discursiviza a tradução, mas, sobretudo, como forma de fazer circular sentidos outros, que possam operar na 
forma da resistência, transformando os saberes em circulação no mercado e na rede, de modo a considerar a tradução como atividade complexa.

\section{REFERÊNCIAS}

ALFARO, Carolina; DIAS, Maria Carmelita P. Tradução Automática: uma ferramenta de auxílio ao tradutor. Cadernos de Tradução. V. 1, n. 3, Florianópolis, UFSC, p. 370-390, 1998. Disponível em https://periodicos.ufsc.br/index.php/traducao/article/view/5392. Acesso em $20 \mathrm{de}$ março de 2005.

AMARAL, M.V.B. Discurso e Relações de Trabalho. Maceió: EduFal, 2005.

ALMEIDA, J.M.F. Breve História da Internet. Repositorium, Universidade do Minho, Portugal, p.1-5, $2005 . \quad$ Disponível em https://repositorium.sdum.uminho.pt/bitstream/1822/3396/1/INTERNET.pdf. Acesso em 22 de fev. de 2019.

CALDAS, B.F.; MELLO, G.C.C. de. Tradução e Tradutores no Brasil: construções discursivas em editais públicos. Anais da 2 ${ }^{\text {a }}$. Jornada Internacional de Estudos do Discurso. Maringá: UEM, 2012. p. 1-15.

CALDAS, B.; MELLO, G. Vozes da Tradução como Profissão: movência de sentidos na Classificação Brasileira de Ocupações. Vozes da tradução, éticas do traduzir. São Paulo: Humanitas, 2014. p. 177-196.

CRONIN, Michael. Translation and Globalizaion. In: MILLAN, C.; BATRINA, F. (Eds.). The Routledge Handbook of Translation Studies. London: Routledge, 2017 [2013]. pp.491-502. CRONIN, Michael. Translation and Globalization. London \& NY: Routledge, 2003.

HARTLEY, Tony. Technology and Translation. In: MUNDAY, Jeremy (Ed.). The Routledge Companion to Translation Studies. London \& NY: Routledge, 2009. pp. 106-127.

LEFEVERE, André. Translation, rewriting and the manipulation of literary fame. London, New York: Routledge, 1992.

LEMOS, A.C. Cibercultura e mobilidade: a era da conexão. Intercom [Sociedade Brasileira de Estudos Interdisciplinares da comunicação]. Rio de Janeiro, pp. 1-17, 2005. Disponível em www.intercom.org.br/papers/nacionais/2005/resumos/r1465-1.pdf. Acesso em 03 de novembro de 2016.

MELLO, G.C.C. de. Tradução e Mercado: uma análise discursiva. Domínios da Lingu@gem, vol. 11, n. 5, UFU, Uberlândia, 1649-1673, 2017.

ORLANDI, E.P. Discurso em análise: sujeito, sentido e ideologia. Campinas: Pontes, 2012.

ORLANDI, E.P. Análise de discurso: princípios e procedimentos. Campinas: Pontes, 1999.

ORLANDI, E.P. Paráfrase e polissemia: a fluidez nos limites do simbólico. Rua, v. 4, n. 1, Campinas, 11-19, 1998.

PÊCHEUX, M. Semântica e Discurso: uma crítica à afirmação do óbvio. Trad. Bras. Campinas: Ed. da Unicamp, 1988 [1975].

SOUZA, Lucília Maria Abrahão e. Ideologia e Rede Eletrônica. Enciclopédia virtual da Análise do Discurso e áreas afins. Niterói: LAS/UFF, 2016. Disponível em http://ufftube.uff.br/video/USK2XO2OAXU2/Ideologia-e-rede-eletr\%C3\%B4nica--

Luc\%C3\%ADlia-Maria-Abrah\%C3\%A3o-e-Sousa-. Acesso em 31 de outubro de 2016.

STUPIELLO, Érica N. de A. Impactos da (r)evolução da Internet para a Pedagogia da Tradução. Em: LIMA, Érica (Org.). Tradução na Era Digital. Belford Roxo: Transitiva, 2017. pp. 79-94. STUPIELLO, Érika N. de A. Ética profissional na tradução assistida por sistemas de memórias. São Paulo: Editora UNESP Digital, 2014.

WEININGER, M.J. TM \& MT na Tradução Técnica Globalizada: tendências e consequências. Cadernos de Tradução, v. 2, n. 14, Florianópolis, UFSC, p. 243-263, 2004. Disponível em https://periodicos.ufsc.br/index.php/traducao/article/view/6483/5977. Acesso em 14 de dezembro de 2018. 
Artigo recebido em: out. de 2019.

Aprovado e revisado em: nov. de 2019.

Publicado em: dezembro de 2019.

Para citar este texto:

CAMPOS, Giovana Cordeiro. Mercado, tradução e rede eletrônica: discursividades em pauta. Entremeios [Revista de Estudos do Discurso, ISSN 2179-3514, on-line, www.entremeios.inf.br], Seção Estudos, Programa de Pós-Graduação em Ciências da Linguagem (PPGCL), Universidade do Vale do Sapucaí (UNIVÁS), Pouso Alegre (MG), vol. 20, Especial, Dossiê "Língua, discurso e trabalho na contemporaneidade", p. 73-84, dez. 2019.

DOI: http://dx.doi.org/10.20337/ISSN2179-3514revistaENTREMEIOSvol20pagina73a84 